Revista Brasileira de Agricultura Irrigada v.14, no.3, p. 4071 - 4085, 2020

ISSN 1982-7679 (On-line)

Fortaleza, CE, INOVAGRI - http://www.inovagri.org.br

DOI: $10.7127 /$ rbai.v14n101167

Protocolo 1167.20 - 06/08/2020 Aprovado em 29/10/2020

\title{
VARIABILIDADE ESPAÇO-TEMPORAL DA QUALIDADE DA ÁGUA EM ÁREA DE AGRICULTURA IRRIGADA
}

\author{
João Marcos de Jesus Sales ${ }^{1}$, Antenor de Oliveira Aguiar Netto ${ }^{2}$, Adnívia Santos Costa Monteiro ${ }^{3}$, \\ Clayton Moura de Carvalho ${ }^{4}$
}

\begin{abstract}
RESUMO
A agricultura irrigada proporciona a produção de alimentos em regiões semiáridas em diferentes épocas do ano, contudo o manejo inadequado pode ocasionar problemas ambientais. Este trabalho teve como objetivo avaliar a influência da agricultura irrigada e da sazonalidade climática nos parâmetros indicadores da qualidade da água da Bacia Escola Jacaré-Curituba. Foram coletados 20 parâmetros da qualidade da água $(\mathrm{pH}$, condutividade elétrica, oxigênio dissolvido, sólidos dissolvidos totais, demanda bioquímica de oxigênio, sólidos em suspensão totais, $\mathrm{NH}_{3}, \mathrm{NO}_{2}, \mathrm{NO}_{3}$, cor aparente, dureza total, salinidade, clorofila-a, sódio, fósforo total, cloretos, alcalinidade total, coliformes termotolerantes, turbidez e temperatura da água), obtidos em seis campanhas de amostragem no período de abril de 2018 a agosto de 2019, determinados conforme descrito no Standard methods e comparados com os valores estabelecidos pela resolução CONAMA 357/2005 e pela classificação das águas para fins de irrigação de acordo com Ayers e Westcot (1994). Na classificação das águas, aplicou-se o diagrama de classificação para fins de irrigação. Os principais impactos na qualidade da água foram observados no período seco. $\mathrm{O}$ escoamento de áreas agrícolas a montante está afetando a qualidade da água. Na classificação das águas de irrigação houve variação entre as classes $\mathrm{C}_{1} \mathrm{~S}_{1}$ na Barragem $(\mathrm{P} 1)$ à $\mathrm{C}_{4} \mathrm{~S}_{3}$ no Ponto de Controle $(\mathrm{P} 2)$.
\end{abstract}

Palavras-chave: Recursos hídricos, sazonalidade climática, semiárido, bacia hidrográfica.

\section{SPACE-TEMPORAL VARIABILITY OF WATER QUALITY IN IRRIGATED AGRICULTURE AREA}

\footnotetext{
ABSTRACT

${ }^{1}$ Mestre em Recursos Hídricos, Universidade Federal de Sergipe, São Cristóvão - SE, e-mail: salles.ufs@ @otmail.com

2 Doutor em Agronomia, Professor do Programa de Pós-Graduação em Recursos Hídricos, Universidade Federal de Sergipe, São Cristóvão - SE, e-mail: antenor.ufs@ gmail.com, orcid: 0000-0002-3555-6776

${ }^{3}$ Doutora em Química, Bolsista PNPD do Programa de Pós-Graduação em Recursos Hídricos, Universidade Federal de Sergipe, São Cristóvão - SE, e-mail: adniviacosta@ hotmail.com, orcid: 0000-0002-7139-898X

${ }^{4}$ Doutor em Engenharia Agrícola, Professor Instituto Federal de Educação, Ciência e Tecnologia Baiano - Campus Serrinha, Serrinha - BA, e-mail: clayton.carvalho@ifbaiano.edu.br, orcid: 0000-0002-4382-5382
} 
Irrigated agriculture provides food production in semiarid regions at different times of the year, however inadequate management can cause environmental problems. This work aimed to evaluate the influence of irrigated agriculture and climatic seasonality in the parameters of water quality in the Jacaré-Curituba School Basin. Twenty water quality parameters were collected ( $\mathrm{pH}$, electrical conductivity, dissolved oxygen, total dissolved solids, biochemical oxygen demand, total suspended solids, $\mathrm{NH}_{3}, \mathrm{NO}_{2}, \mathrm{NO}_{3}$, apparent color, total hardness, salinity, chlorophyll-a, sodium, total phosphorus, chlorides, total alkalinity, thermotolerant coliforms, turbidity and water temperature), obtained in six sampling campaigns from April 2018 to August 2019, determined as described in the Standard methods and compared with the values established by the resolution CONAMA 357/2005 and for the classification of waters for irrigation purposes according to Ayers and Westcot (1994). In the classification of waters, the classification diagram for irrigation purposes was applied. The main impacts on water quality were observed in the dry period. Runoff from upstream agricultural areas is affecting water quality. In the classification of irrigation water there was variation between classes $\mathrm{C}_{1} \mathrm{~S}_{1}$ in the Dam (P1) to $\mathrm{C}_{4} \mathrm{~S}_{3}$ in the Control Point (P2).

Keywords: Water resources, climatic seasonality, semiarid, hydrographic basin.

\section{INTRODUÇÃO}

A água é fundamental para a existência de vida. Entretanto, várias partes do mundo sofrem com uma crise hídrica decorrente, principalmente, da má distribuição espaçotemporal das precipitações, aumento da demanda pelo crescimento populacional e de um gerenciamento limitado. Esses fatores contribuem para o aumento da competitividade entre os diferentes setores que demandam água (CARVALHO et al., 2020b).

A agricultura irrigada proporciona $\mathrm{o}$ aumento da produção de alimentos em diferentes épocas do ano e condições climáticas em virtude da demanda mundial por água e alimento, contudo, o manejo inadequado da irrigação e drenagem são umas das principais fontes de poluição difusa dos corpos hídricos superficiais e subterrâneos. Ou seja, nesses ambientes os impactos das atividades agrícolas são cada vez mais importantes na gestão de recursos hídricos (LOMBA et al., 2017, XIE et al., 2018, SINGH, 2019).

Nos últimos anos, tem-se discutido com maior frequência a temática dos recursos hídricos em terras agrícolas, enfatizando-se as perdas em qualidade e quantidade quando adotado plantios sucessivos, aumento da aplicação de agroquímicos, manejos incorretos dos solos e insumos fertilizantes e agrotóxicos nas lavouras e pastagens ameaça a sustentabilidade hídrica especialmente em regiões árida e semiáridas.

É de grande importância à identificação da qualidade da água, bem como verificar a sua vulnerabilidade à atividade humana, para que seja realizada uma gestão adequada dos recursos hídricos no que se refere ao seu gerenciamento, uso e conservação (SANTI et al., 2012; CARVALHO et al., 2017b).

O monitoramento que determina ações de planejamento para conservação do recurso água se faz necessário, pois as características da qualidade da água variam de acordo com o espaço e o tempo, podendo determinar muitas características hídricas em locais e períodos diferentes, o que gera um grande número de informações correlacionadas (BERTOSSI et al., 2013; CARVALHO et al., 2017a; CARVALHO et al., 2020a).

Deste modo, esta pesquisa teve como objetivo avaliar a influência da agricultura irrigada e da sazonalidade climática nos parâmetros indicadores da qualidade da água da Bacia Escola Jacaré-Curituba.

\section{MATERIAL E MÉTODOS}

A área de estudo corresponde à Bacia Escola Jacaré-Curituba, localizada no semiárido nordestino na região do baixo São Francisco sergipano, entre os municípios de Canindé do São Francisco-SE e de Poço Redondo-SE (Figura 1). Esse estudo foi 


\section{VARIABILIDADE ESPAÇO-TEMPORAL DA QUALIDADE DA ÁGUA EM ÁREA DE AGRICULTURA IRRIGADA}

realizado com dados obtidos em seis campanhas de amostragem no período de abril de 2018 a agosto de 2019 .

A bacia hidrográfica escola foi implantada no ano de 2015 em um riacho afluente do rio Jacaré, importante afluente da margem direita do rio São Francisco, situada no Assentamento de reforma agrária Jacaré Curituba, no Estado de Sergipe com aproximadamente 700 famílias de agricultores familiares (AGUIAR NETTO et al., 2016; SALES et al., 2018).

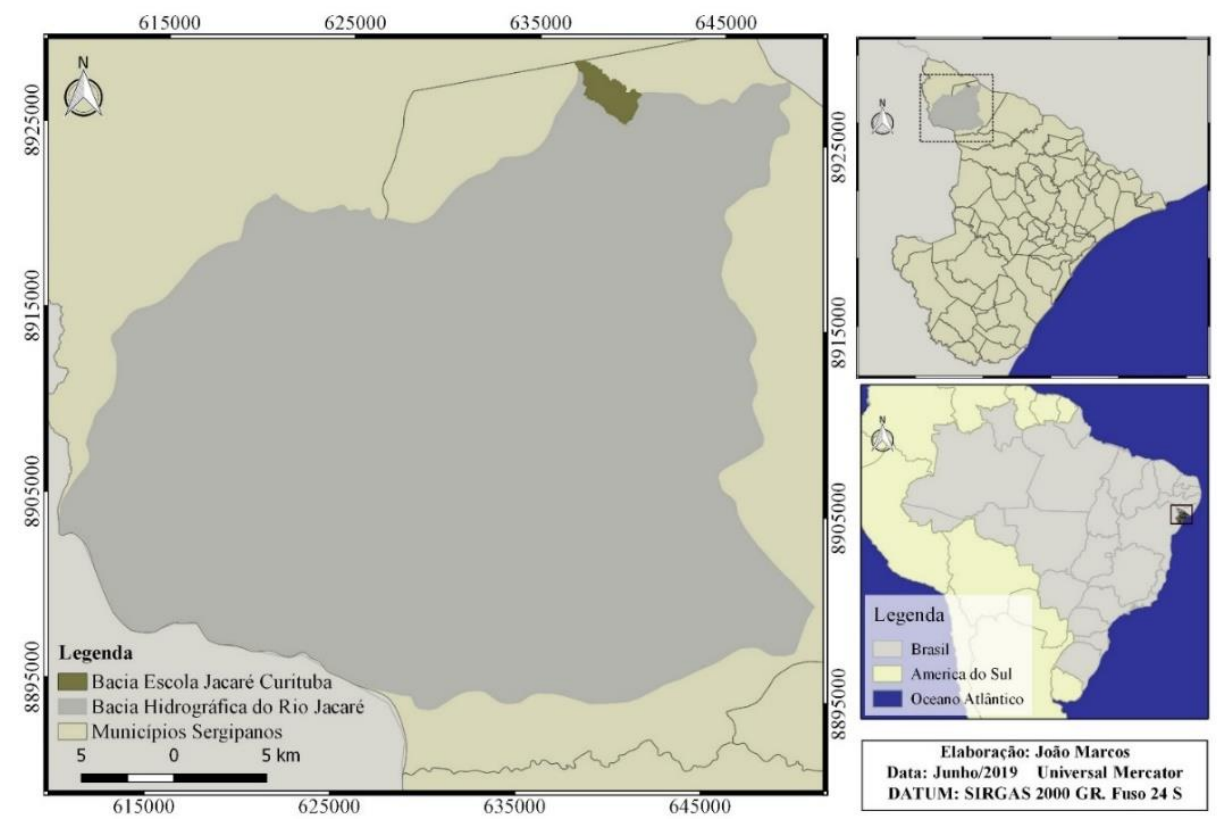

Figura 1. Localização da área de estudo no Estado de Sergipe e Brasil.

Segundo a classificação climática de Köppen (1948), o clima é do tipo Bsh', clima muito quente, semiárido, tipo estepe, Caatinga hiperxerófila com estação chuvosa no inverno compreendendo os meses de abril a julho e seco durante os meses restantes do ano com precipitações baixas e irregulares. A pluviosidade média anual situa-se em 552,25 $\mathrm{mm}$ e evapotranspiração superior a $1.500 \mathrm{~mm}$ anuais. Os solos na região são predominantemente do tipo Luvissolo
Crômico, são rasos com textura franco argilosa com dificuldade de drenagem e boa fertilidade (EMBRAPA, 2018).

As médias das características climáticas na região para o período de 1980 a 2016 de acordo com o banco de dados disponibilizado por Xavier et al. (2015) em conjunto com a vazão média mensal coletada pela Calha Parshall localizada no ponto 2 da coleta de dados (ponto de controle) são apresentados na Figura 2.

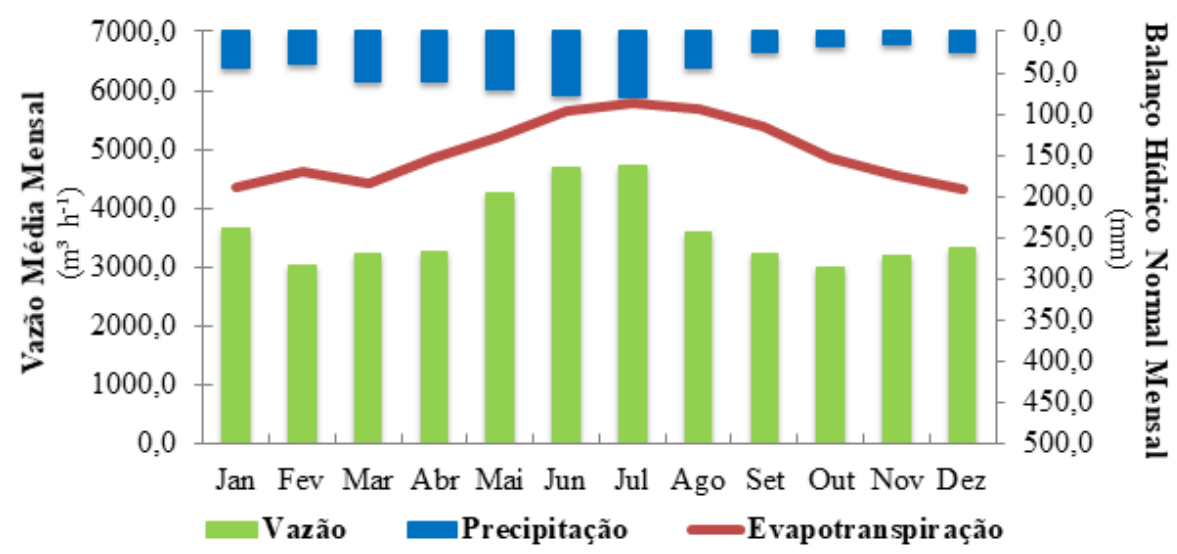

Figura 2. Dados hidrológicos mensais da bacia escola Jacaré Curituba. 
Em relação ao mapa de uso/ocupação do solo, foi elaborado através de softwares livres Qgis versão 2.6.1, com técnicas de geoprocessamento, com trabalhos de campo e com ortofotos digitais, obtidas a partir do Gaofen-2, georreferenciadas, com coordenadas na projeção UTM (Universal Transversa de Mercator), Modelo da Terra pertencente ao
Sistema de Referência Geocêntrico para as Américas, conhecido como SIRGAS2000, contidos na zona $24 \mathrm{~S}$, recortada a partir da máscara da bacia do Escola Jacaré Curituba, posteriormente essa imagem foi processada e criou-se o mapa de uso e ocupação atual presente na área de estudo (Figura 3).

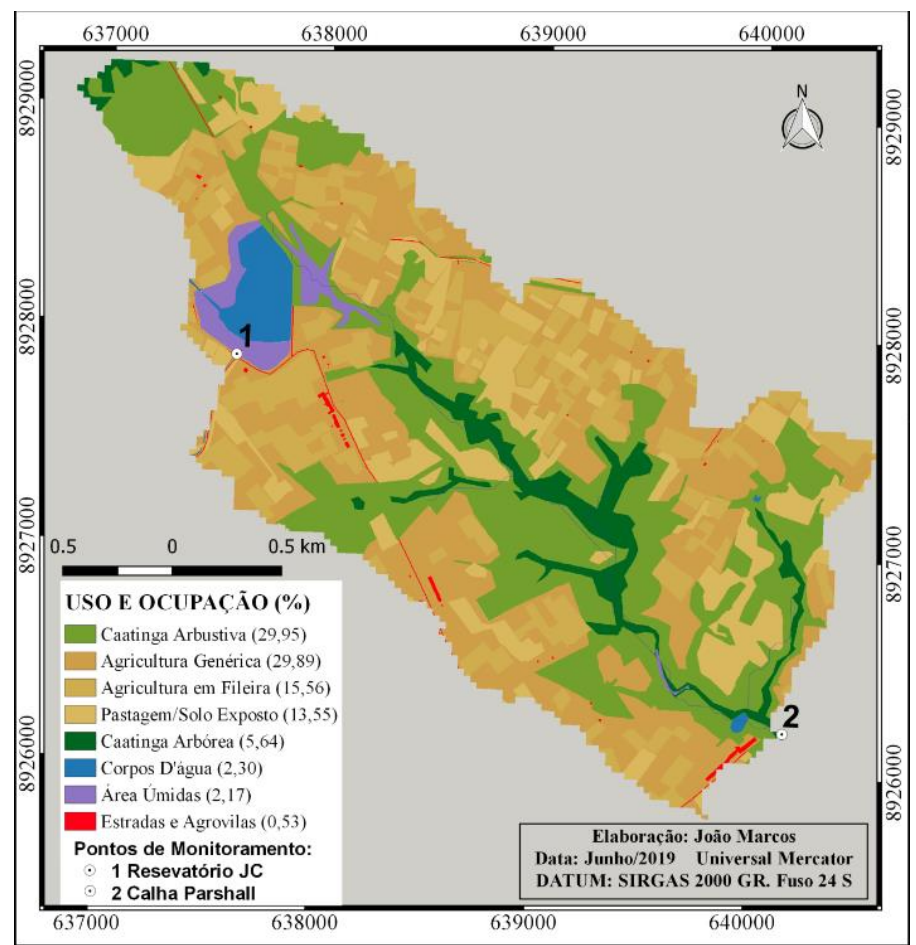

Figura 3. Localização dos pontos de amostragem para fins de qualidade da água e o uso e ocupação da terra da Bacia Escola Jacaré Curituba.

A escolha dos locais de amostragem foi selecionada de forma programada, considerando a acessibilidade e finalidade de representação da bacia, compreendendo os diferentes usos e ocupação do solo, distribuídos em 2 locais da bacia escola Jacaré-Curituba (Figura 3).

A primeira estação de monitoramento foi localizada na saída da barragem para o canal de irrigação (P1) que tem a finalidade de abastecer o sistema de irrigação do Assentamento Jacaré - Curituba, esse reservatório está a $3 \mathrm{~km}$ do ponto de controle. A segunda estação (P2) correspondente ao Ponto de controle foi localizada no medidor tipo Calha Parshall instalado no centro de difusão, onde desde 2015 são realizadas as medições de vazão diárias.

As campanhas de amostragem foram realizadas em diferentes períodos para avaliar a influência da sazonalidade na qualidade das águas dos locais estudados. O período sazonal definido seguindo as características climáticas mensais, foi identificado como úmidos (meses com maiores precipitações), secos (meses com baixas precipitações) e a zona intermediária, conforme descrito na Tabela 1 
Tabela 1. Estações de monitoramento na bacia escola Jacaré-Curituba, Poço Redondo/SE. IDENTIFICAÇÃO DE AMOSTRAGEM

\begin{tabular}{cc}
\hline Barragem Jacaré-Curituba $(\mathrm{P} 1)$ & Calha Parshall $(\mathrm{P} 2)$ \\
UTM 24L 637599; 8927866 & UTM 24L 640139; $8926218-$ \\
\hline PERÍODO SAZONAL & MÊS/ANO \\
\hline Transição Seco-Úmido $\left(\mathrm{t}^{1}\right)$ & Abril/2018 \\
Úmido $\left(\mathrm{u}^{1}\right)$ & Julho/2018 \\
Seco $\left(\mathrm{s}^{1}\right)$ & Novembro/2018 \\
Seco $\left(\mathrm{s}^{2}\right)$ & Janeiro/2019 \\
Úmido $\left(\mathrm{u}^{2}\right)$ & Maio/2019 \\
Transição Seco- Úmido $\left(\mathrm{t}^{2}\right)$ & Agosto/2019
\end{tabular}

${ }^{1} \mathrm{e}^{2}$ Correspondem ao primeiro e segundo período sazonal, respectivamente.

Em cada ponto foram coletadas amostras de água na camada superficial em frascos plásticos, que foram previamente limpos. Todos os procedimentos de coleta, conservação e análise obedeceram às metodologias descritas no Standard Methods for the Examination of Water and Wastewater (APHA, 2017). Os parâmetros e métodos de análise utilizados estão descritos na Tabela 2 .

Tabela 2. Parâmetros físico-químicos e biológicos e respectivos métodos de análise utilizados para a avaliação da qualidade da água.

\begin{tabular}{|c|c|c|c|c|}
\hline Parâmetros & Sigla & Unidade & LQ & Método \\
\hline $\mathrm{pH}$ & - & -- & $1-12$ & SMEWW, 2012, $4500 \mathrm{H}+\mathrm{B}$ \\
\hline Condutividade Elétrica & $\mathrm{CE}$ & $\mathrm{dS} \mathrm{m}^{-1}$ & 0,01 & SMEWW, 2012, 2510 B \\
\hline Oxigênio Dissolvido & OD & $\mathrm{mg} \mathrm{L}^{-1}$ & 0,04 & SMEWW, 2012, 4500-O C \\
\hline Sólidos Dissolvidos Totais & STD & $\mathrm{mg} \mathrm{L}^{-1}$ & 0,006 & SMEWW, 2012, 2510 A \\
\hline Demanda Bioquímica de Oxigênio & DBO & $\mathrm{mg} \mathrm{L}^{-1}$ & 0,5 & SMEWW, 2012, 5210-D \\
\hline Sólidos em Suspensão Totais & SST & $\mathrm{mg} \mathrm{L}^{-1}$ & -- & SMEWW, 2012, 2540 D \\
\hline Nitrogênio - Amoniacal & $\mathrm{NH}_{3}$ & $\mathrm{mg} \mathrm{L}^{-1}$ & 0,012 & SMEWW,2012, 4500-NH $\mathrm{NH}_{3}$ \\
\hline Nitrogênio - Nitrito & $\mathrm{NO}_{2}$ & $\mathrm{mg} \mathrm{L}^{-1}$ & 0,0009 & SMEWW,2012, 4500- $\mathrm{NO}_{2} \mathrm{~B}$ \\
\hline Nitrogênio - Nitrato & $\mathrm{NO}_{3}^{-}$ & $\mathrm{mg} \mathrm{L}^{-1}$ & 0,026 & SMEWW, 2012, 4500- $\mathrm{NO}_{3} \mathrm{C}$ \\
\hline Cor Aparente & Cor & $\mathrm{uH}$ & 0,02 & SMEWW, 2012, 2120 C \\
\hline Dureza Total & DT & $\mathrm{mg} \mathrm{L}^{-1}$ & 2,00 & SMEWW, 2012, $2340 \mathrm{C}$ \\
\hline Temperatura da água & Temp & ${ }^{\circ} \mathrm{C}$ & 0,10 & (ensaio de campo) \\
\hline Salinidade & SAL & $\mathrm{g} \mathrm{Kg}^{-1}$ & 0,01 & SMEWW, 2012, $2520 \mathrm{~B}$ \\
\hline Clorofila a & $\mathrm{Cl}-\mathrm{a}$ & $\mu \mathrm{g} \mathrm{L}^{-1}$ & 0,01 & SMEWW, 2012, $10200 \mathrm{H}$ \\
\hline Sódio & $\mathrm{Na}^{+}$ & $\mathrm{mg} \mathrm{L}^{-1}$ & 0,0043 & ICP OES \\
\hline Fósforo Total (RBLE) & $\mathrm{Pt}$ & $\mathrm{mg} \mathrm{L}^{-1}$ & 0,0067 & SMEWW, 2012, 4500-P B,E \\
\hline Cloretos (RBLE) & $\mathrm{Cl}^{-}$ & $\mathrm{mg} \mathrm{L}^{-1}$ & 2,42 & SMEWW, 2012, 4500-Cl B \\
\hline Alcalinidade Total (RBLE) & Alc & $\mathrm{mg} \mathrm{L}^{-1}$ & 5,22 & SMEWW, 2012, 2320 B \\
\hline Coliformes Termotolerantes & Coli & NMP $100 \mathrm{~mL}^{-1}$ & -- & SMEWW9221B \\
\hline Turbidez & $\operatorname{Tr}$ & ut & 0,01 & SMEWW, 2017, 2130 B \\
\hline
\end{tabular}

SMEWW: Standard Methods for the Examination of Water and Wastewater, APHA, 23 ${ }^{\mathrm{a}}$. ed.,Washington, 2017; ICP OES: Espectrofotometria de Emissão Atômica com Plasma Indutivamente Acoplado; LQ: Limite de Quantificação do Método.

Para classificação da qualidade das águas, foram aplicados os valores estabelecidos pelo Conselho Nacional do Meio Ambiente (CONAMA) através da Resolução 357/2005 (BRASIL, 2005) e pela classificação das águas para fins de irrigação de acordo com Ayers e Westcot (1994).

Utilizou-se o diagrama para classificação das águas para fins de irrigação pela metodologia sugerida pelo United States Salinity Laboratory - USSL (RICHARDS, 1954), em que a concentração total de sais e ou condutividade elétrica, combinada com a Razão de Adsorção de Sódio (RAS), permitem formar até vinte classes de água para irrigação. Os resultados do diagrama oscilam entre os de risco de salinidade $\mathrm{C}_{1}$ a $\mathrm{C}_{4}$ e os riscos de problemas de infiltração no solo causado pela 
sodicidade da água de $\mathrm{S}_{1}$ a $\mathrm{S}_{4}$ em todas as combinações possíveis.

\section{RESULTADOS E DISCUSSÃO}

De acordo com os resultados obtidos para uso e ocupação da terra conforme a Figura 3, a maior parte da Bacia Escola Jacaré-Curituba encontra-se ocupada pela agricultura irrigada, uma porcentagem igual a $45,45 \%$ da área de estudo. Nessas áreas a aplicação dos fertilizantes é realizada na época de plantio e em manutenção, enquanto a aplicação de defensivos agrícolas não possui período fixo. Associada ainda a agricultura e pecuária a área ocupada com pastagem e solos expostos alcança $13,55 \%$ nessa bacia.
Já a área referente à Caatinga e preservação da mata ciliar, foi classificada em Caatinga arbustiva sendo representada por $29,95 \%$ da área total da bacia, enquanto que a Caatinga Arbórea encontra-se em apenas $5,64 \%$ da terra localizada em áreas protegidas. Em menores proporções de ocupação das terras na Bacia Escola os corpos hídricos e as áreas úmidas ocupam 2,30\% e $2,17 \%$ respectivamente, as estradas, agrovilas e infraestruturas com $0,5 \%$.

Em geral os valores dos parâmetros avaliados da qualidade da água encontrados no Ponto de Controle (Calha Parshal - P1) foram superiores aos da água oriunda da Barragem Jacaré Curituba (Barragem - P2) (Tabela 3).

Tabela 3. Resumo estatístico da composição das variáveis da qualidade das águas da Bacia Escola Jacaré Curituba, Poço Redondo-SE.

\begin{tabular}{|c|c|c|c|c|c|c|c|c|}
\hline \multirow[b]{2}{*}{ Parâmetros } & \multicolumn{4}{|c|}{ Barragem Jacaré Curituba (P1) } & \multicolumn{4}{|c|}{ Calha Parshal (P2) } \\
\hline & Média & $\mathrm{DP}$ & Mínimo & Máximo & Média & $\mathrm{DP}$ & Mínimo & Máximo \\
\hline $\mathrm{pH}$ & 8,47 & 0,50 & 7,92 & 9,10 & 8,24 & 0,11 & 8,07 & 8,37 \\
\hline $\mathrm{CE}\left(\mathrm{dS} \mathrm{m} \mathrm{m}^{-1}\right)$ & 0,54 & 1,14 & 0,007 & 2,87 & 2,76 & 0,64 & 2,14 & 3,97 \\
\hline $\mathrm{OD}\left(\mathrm{mg} \mathrm{L}^{-1}\right)$ & 9,00 & 2,08 & 5,22 & 11,57 & 7,10 & 0,88 & 6,05 & 8,62 \\
\hline $\operatorname{SDT}\left(\mathrm{mg} \mathrm{L}^{-1}\right)$ & 47,91 & 5,29 & 41,87 & 54,63 & $1.409,17$ & 121,70 & $1.197,00$ & $1.556,00$ \\
\hline $\mathrm{DBO}\left(\mathrm{mg} \mathrm{L}^{-1}\right)$ & 19,82 & 22,62 & 0,50 & 64,00 & 9,33 & 9,03 & 0,50 & 25,00 \\
\hline $\operatorname{SST}\left(\mathrm{mg} \mathrm{L}^{-1}\right)$ & 12,50 & 23,82 & 1,00 & 61,00 & 10,17 & 9,15 & 3,00 & 28,00 \\
\hline $\mathrm{NH}_{3}\left(\mathrm{mg} \mathrm{L}^{-1}\right)$ & 0,04 & 0,03 & 0,01 & 0,08 & 0,03 & 0,02 & 0,02 & 0,06 \\
\hline $\mathrm{NO}_{2}\left(\mathrm{mg} \mathrm{L}^{-1}\right)$ & 0,04 & 0,05 & 0,00 & 0,14 & 0,62 & 1,33 & 0,01 & 3,33 \\
\hline $\mathrm{NO} 3\left(\mathrm{mg} \mathrm{L}^{-1}\right)$ & 0,51 & 1,02 & 0,00 & 2,57 & 0,94 & 1,13 & 0,01 & 2,62 \\
\hline $\mathrm{COR}(\mathrm{uH})$ & 6,73 & 14,39 & 0,60 & 36,10 & 15,64 & 28,22 & 0,50 & 72,90 \\
\hline $\mathrm{DT}\left(\mathrm{mg} \mathrm{L}^{-1}\right)$ & 33,28 & 7,17 & 24,74 & 41,09 & $1.204,08$ & 740,04 & 514,10 & $2.350,00$ \\
\hline $\operatorname{SAL}\left(\mathrm{g} \mathrm{Kg}^{-1}\right)$ & 0,27 & 0,59 & 0,02 & 1,48 & 1,51 & 0,31 & 1,18 & 2,09 \\
\hline $\mathrm{Cl}-\mathrm{a}$ & 1,22 & 1,35 & 0,01 & 3,75 & 3,92 & 2,12 & 0,01 & 5,52 \\
\hline $\mathrm{Na}\left(\mathrm{mg} \mathrm{L}^{-1}\right)$ & 42,44 & 95,32 & 1,20 & 237,00 & 324,83 & 12,89 & 312,00 & 340,00 \\
\hline PT $\left(\mathrm{mg} \mathrm{L}^{-1}\right)$ & 0,03 & 0,01 & 0,02 & 0,04 & 0,06 & 0,03 & 0,04 & 0,10 \\
\hline $\mathrm{Cl}\left(\mathrm{mg} \mathrm{L}^{-1}\right)$ & 4,08 & 0,59 & 3,35 & 5,00 & 510,58 & 39,42 & 462,70 & 573,10 \\
\hline $\operatorname{ALC}\left(\mathrm{mg} \mathrm{L}^{-1}\right)$ & 40,13 & 8,20 & 31,74 & 54,22 & 550,77 & 95,76 & 476,10 & 699,30 \\
\hline Coli (NMP $100 \mathrm{~mL}^{-1}$ ) & $3.426,50$ & $3.140,80$ & 79,00 & $6.800,00$ & 926,67 & 724,81 & 170,00 & $1.700,00$ \\
\hline $\operatorname{Tr}$ (ut) & 2,42 & 3,61 & 0,20 & 9,60 & 2,10 & 1,34 & 0,60 & 4,30 \\
\hline Temp $\left({ }^{\circ} \mathrm{C}\right)$ & 28,63 & 1,76 & 26,54 & 31,17 & 28,35 & 1,82 & 24,74 & 29,85 \\
\hline
\end{tabular}

pH: potencial hidrogeniônico; CE: Condutividade Elétrica; OD: Oxigênio Dissolvido; SDT: Sólidos Dissolvidos Totais; DBO: Demanda Bioquímica de Oxigênio; SST: Sólidos em Suspensão Totais; $\mathrm{NH}_{3}$ : Nitrogênio - Amoniacal; $\mathrm{NO}_{2}$ : Nitrogênio - Nitrito; $\mathrm{NO}_{3}$ : Nitrogênio - Nitrato; COR: Cor Aparente; DT: Dureza Total; SAL: Salinidade; Cl-a: Clorofila a; Na: Sódio; PT: Fósforo Total; Cl: Cloretos; ALC: Alcalinidade Total; Coli: Coliformes Termotolerantes; Tz: Turbidez; T: Temperatura da Água; DP: Desvio Padrão..

\section{Indicadores Físicos da Qualidade da Água}

Analisando a Figura 4A observa-se que a cor da água no Ponto de Controle (P2) é relativamente maior que os teores encontrados na Barragem (P1), obtendo variações médias de $6,73 \mathrm{uH}$ em P1 e de 15,64 uH em P2. Von Sperling (2007) e Skoronski et al. (2014) citam que essas alterações na cor da água dos mananciais podem ser provenientes de causas naturais, (decomposição vegetal, algas, tanino, lignina $e$ os minerais dissolvidos "complexo de ferro e manganês") e de causas antrópicas (lançamento de efluentes). 
Em relação à temperatura da água, os resultados obtidos mostram que existe baixa variação ao longo do período analisado em ambos os locais estudados (Figura 4B), sendo que a temperatura no período chuvoso variou de 24,74 a $28,74^{\circ} \mathrm{C}$, e no período de estiagem a variação foi de 28,75 a $31,17^{\circ} \mathrm{C}$.

$$
\text { A. } \begin{array}{cc}
75 \\
\text { ¿ } & 50 \\
\hline & 25
\end{array}
$$
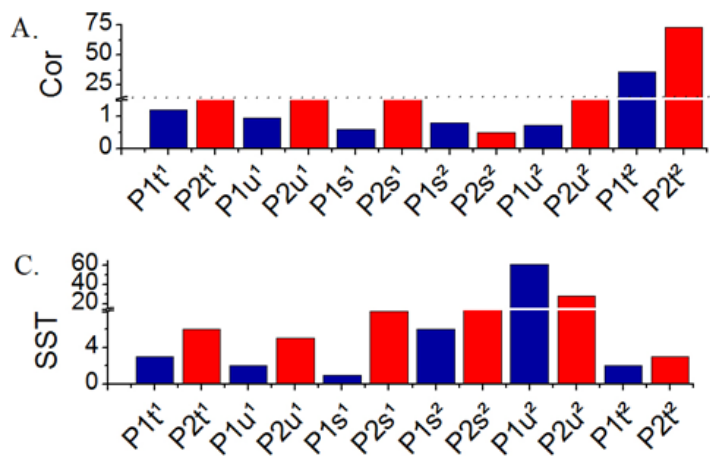

CONAMA 357 (30)

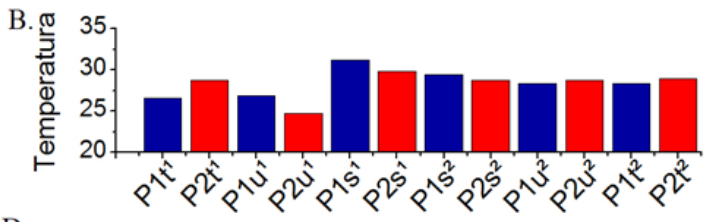

D.

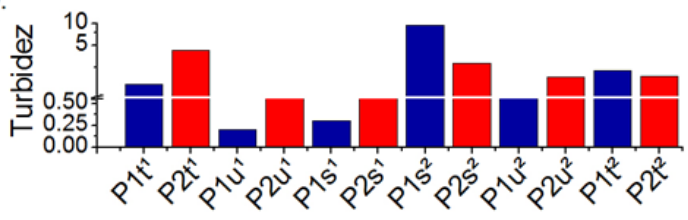

Figura 4. Resultados dos indicadores físicos da qualidade da água na Bacia Escola Jacaré Curituba em três períodos de amostragem [seco(s), úmido(u) e a transição(t)] entre os anos de 2018 a 2019.P1(Barragem) e P2(Ponto de Controle).

O menor valor observado ocorreu no período úmido em $\mathrm{P} 2 \mathrm{u}^{1}$, durante este período da coleta de dados, as condições climáticas se caracterizavam pela presença de chuvas constantes durante o mês de julho.

Resultados semelhantes foram encontrados por Britto et al. (2016) ao analisarem os impactos da produção do arroz inundado na qualidade da água do Rio Betume no Estado de Sergipe. Esses mesmos autores encontraram valores de temperatura no período seco (meses com poucas precipitações) variando de 26,2 a $29,72{ }^{\circ} \mathrm{C}$ e no período chuvoso variando de 25,86 a $28,63{ }^{\circ} \mathrm{C}$.

Os sólidos em suspensão totais (SST) apresentaram valores entre 1 a $61 \mathrm{mg} \mathrm{L}^{-1}$ na Barragem (P1) e 3 a $28 \mathrm{mg} \mathrm{L}^{-1}$ no Ponto de Controle (P2) (Figura 4C). O valor máximo permitido de turbidez na água distribuída é de 5,0 NTU, sendo que os valores encontrados nas águas analisadas variaram de 0,20 a 9,60 NTU, correspondente ao ponto da Barragem durante o mês de janeiro de 2019 (Figura 4D), de acordo com a resolução está acima do limite estabelecido CONAMA 357 (BRASIL, 2005).

Britto et al. (2016) afirmam que o aumento dos valores de turbidez ocorre possivelmente devido à presença de sólidos em suspensão, tais como partículas inorgânicas (areia, silte, argila) e detritos orgânicos, tais como algas e bactérias, plâncton.

\section{Indicadores Químicos da Qualidade da Água}

$\mathrm{O}$ pH é um parâmetro que caracteriza o grau de acidez ou de alcalinidade da água ou do solo. $\mathrm{O} \mathrm{pH}$ da água medido nos dois locais de estudo variou entre 7,92 e 9,10 no período seco (Ps), entre 8,15 e 9,05 para o período de transição $(\mathrm{Pt})$ e de 8,01 a 8,34, para o período úmido $(\mathrm{Pu})$ entre os pontos de coleta. O maior valor de 9,10 registrado durante a pesquisa foi observado em $\left(\mathrm{P} 1 \mathrm{~s}^{1}\right)$. No geral, o $\mathrm{pH}$ das águas dos locais estudados foi classificado como normal, variando de neutro a levemente alcalino (Figura $5 \mathrm{~A})$.

A resolução CONAMA 357/05 (BRASIL, 2005) descreve que quase todas as amostras estudadas $(83,3 \%)$ foram classificadas na faixa normal de $\mathrm{pH}(6,0$ - 9,0). Neste estudo foram observados valores acima de 8,5 nas águas da barragem em novembro (P1s $\left.{ }^{1}\right)$ e em agosto de 2019 no mesmo ponto de amostragem $\left(\mathrm{P}^{2} \mathrm{t}^{2}\right)$, época que houve diminuição no nível do reservatório. $\mathrm{O} \mathrm{pH}$ acima de 8,5 favorece ao entupimento nos sistemas de irrigação localizados e pode ser fator limitante em relação a algumas culturas. 
Sales et al.
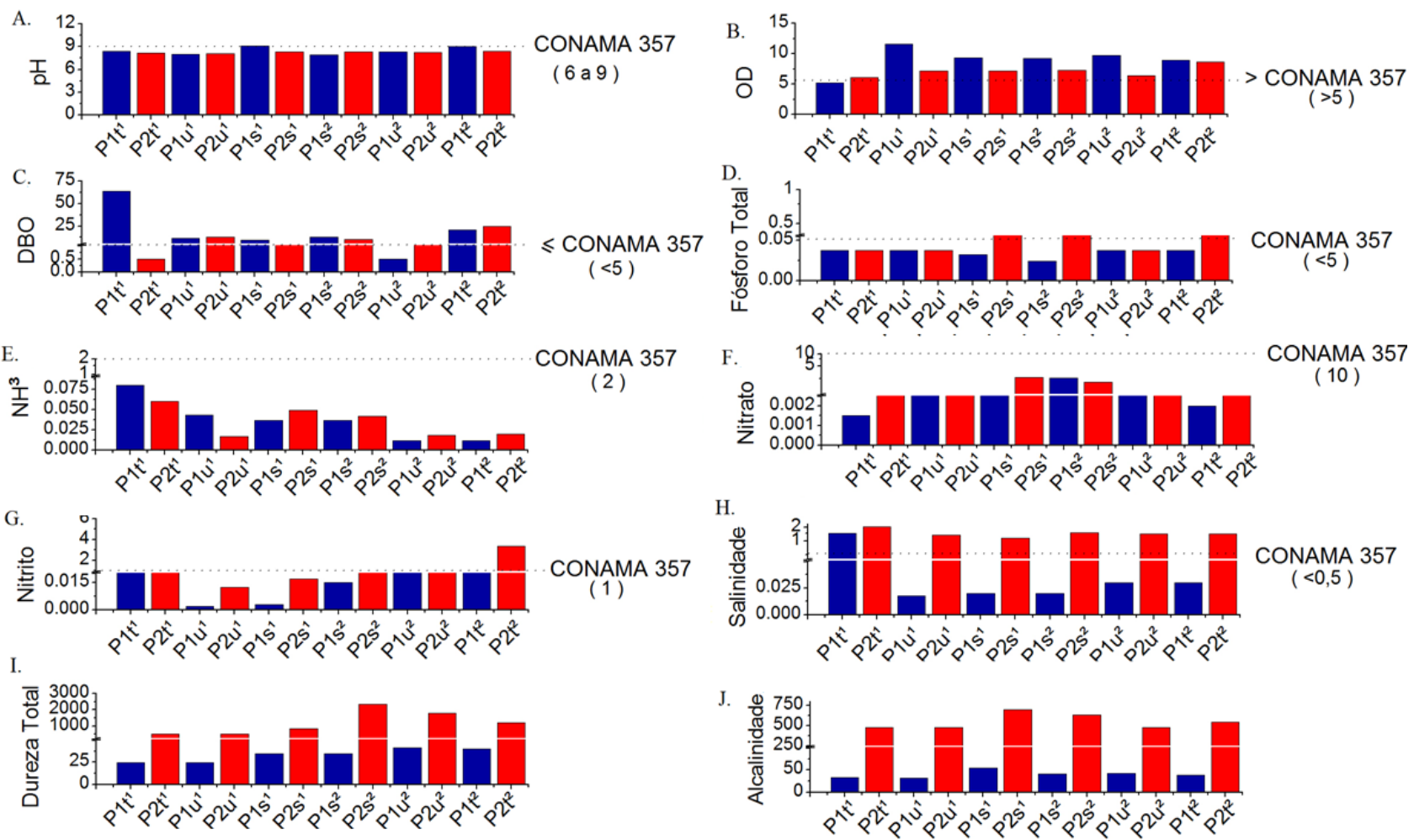

Figura 5. Resultados dos indicadores químicos da qualidade da água na Bacia Escola Jacaré Curituba em três períodos de amostragem [seco(s), úmido(u) e a transição(t)] entre os anos de 2018 a 2019.P1(Barragem) e P2(Ponto de Controle).

Sales et al. (2018) enfatizam que os solos da região de estudo são levemente alcalinos, fato esse que pode justificar a ocorrência de $\mathrm{pH}$ com característica neutra a alcalina, pois o escoamento da água arrasta componentes dos solos e pode influenciar os resultados de $\mathrm{pH}$.

As concentrações de oxigênio dissolvido (OD) estabelecidas pela Resolução CONAMA 357/2005 (BRASIL, 2005) devem apresentar um limite mínimo de $5 \mathrm{mg} \mathrm{L}^{-1}$ de OD; desta maneira, os valores analisados nos dois locais de amostragem (Figura 5B), atenderam à legislação para água doce classe 2 em todos os períodos estudados.

Resultado semelhante foi obtido por Sassoma et al. (2015) ao analisarem a qualidade da água do Rio Catumbela na Angola, por Valle Júnior et al. (2013) ao analisarem a qualidade da água do Rio Uberaba - MG e por Vasconcelos et al. (2009) ao analisarem a qualidade da água do Rio Acaraú $-\mathrm{CE}$.

Os valores da Demanda Bioquímica de Oxigênio (DBO) variaram de 0,5 a $64,0 \mathrm{mg} \mathrm{L}^{-}$ ${ }^{1}$, na Barragem (P1) e em relação ao Ponto de Controle (P2) os valores encontrados ficaram entre 0,5 a $25 \mathrm{mg} \mathrm{L}^{-1}$. Os valores da DBO apresentados na Figura 5C, mostra que em ambos os pontos foram semelhantes em relação ao período seco e chuvoso, sendo o maior valor (64 $\mathrm{mg} \mathrm{L}^{-1}$ ) registrado no reservatório durante o período de transição seco e chuvoso $\left(\mathrm{P}^{1} \mathrm{t}^{1}\right)$.

$\mathrm{O}$ aumento da DBO durante esse período provavelmente ocorre devido ao aumento dos níveis da matéria orgânica, tal como reportado por Britto et al. (2018), onde a maior concentração da matéria orgânica no corpo d'água ocorreu no período seco resultante da evapotranspiração na região. Foram observados valores acima do máximo estabelecido para DBO (até $5 \mathrm{mg} \mathrm{L}^{-1}$ ), apenas para os períodos $\left(\mathrm{P} 1 \mathrm{t}^{1}, \mathrm{P} 1 \mathrm{t}^{2}\right.$ e $\left.\mathrm{P} 2 \mathrm{t}^{2}\right)$.

Durante o monitoramento hídrico na Bacia Escola Jacaré-Curituba verificou-se que o fósforo total (PT) registrado na Barragem (P1) apresentou valores médios entre 0,028 a $0,037 \mathrm{mg} \mathrm{L}^{-1}$, enquanto que na região do Ponto de Controle (P2) foram observados valores situados na faixa de 0,037 a $0,087 \mathrm{mg} \mathrm{L}^{-1}$.

Os maiores valores observados ocorreram no período de estiagem em $\mathrm{P} 2 \mathrm{~s}^{1} \mathrm{e}$ $\mathrm{P} 2 \mathrm{~s}^{2}$ (Figura 5D), sendo esses valores acima do máximo permissível pelo CONAMA (BRASIL, 2005). Esse fato pode ser explicado 
com a diminuição das chuvas e a aplicação de fertilizantes fosfatados, cuja origem são os excedentes da água de drenagem agrícola. Além disso, no período chuvoso, o escoamento superficial das águas das chuvas é somado aos excedentes da irrigação, favorecendo a diluição das concentrações de fósforo. Esses resultados diferem do padrão encontrado por Britto et al. (2018), que registraram maiores valores no período chuvoso em que o autor destaca os mecanismos do escoamento superficial.

Em bacias hidrográficas que possuem uso para fins de agricultura irrigada, o aumento das concentrações de fosforo e nitrogênio pode estar associado as práticas agrícolas, irrigação, uso intensivo de fertilizantes, revolvimento do solo, erosão do solo e a drenagem. Promovem o crescimento excessivo de algas em consequência do processo de eutrofização e expõe ainda a problemas com a redução do oxigênio dissolvido e aumento da taxa de decomposição da matéria orgânica (SCHINDLER et al., 2012). Durante a pesquisa foi observada a presença de macrófitas aquática que são possíveis indicadores do aporte de nutrientes no sistema natural.

Conforme apresentado na Figura 5E em relação a $\mathrm{NH}_{3}$ os valores encontrados ficaram entre 0,012 a $0,08 \mathrm{mg} \mathrm{L}^{-1}$ na Barragem (P1) e entre 0,017 a $0,06 \mathrm{mg} \mathrm{L}^{-1}$ no Ponto de Controle $(\mathrm{P} 2)$, o Nitrito $\left(\mathrm{NO}_{2}\right)$ na Barragem variou de 0,002 a $0,14 \mathrm{mg} \mathrm{L}^{-1}$ e no Ponto de Controle (P2) foram encontrados valores entre 0,123 e 3,331 $\mathrm{mg} \mathrm{L}^{-1}$ (Figura 5F), enquanto para o Nitrato $\left(\mathrm{NO}_{3}\right)$ na Barragem (P1) foram encontrados valores de 0,018 a $2,565 \mathrm{mg} \mathrm{L}^{-1}$ e no Ponto de Controle (P2) valores de 0,012 a $2,62 \mathrm{mg} \mathrm{L}^{-1}$ (Figura 5G). Com exceção dos resultados do Nitrito obtidos durante o mês de agosto de 2019, o qual foi 3 vezes superior ao valor máximo permissível pelo CONAMA (BRASIL, 2005), todos os demais valores encontrados para as formas de nitrogênio estão abaixo dos valores fixados pela legislação.

Essa presença de nitritos nos mananciais indica introdução recente destes compostos nas águas, pois estes são instáveis e oxidam-se facilmente para nitratos (SASSOMA et al., 2015), sendo que a presença pode estar associada tanto às fontes naturais (dissolução dos solos) quanto antropogênicas (do uso de fertilizantes e despejos domésticos) e podem ser transportados para os rios em razão da drenagem das águas em áreas agrícolas e urbanas (KUMAR et al., 2017).

Os resultados da salinidade podem ser observados na Figura 5H, sendo as variações médias desse parâmetro de $0,27 \mathrm{~g} \mathrm{~kg}^{-1}$ na Barragem (P1) e de $1,51 \mathrm{~g} \mathrm{~kg}^{-1}$ no Ponto de Controle (P2). O teor de sais dissolvidos presente no corpo hídrico é indispensável em estudos para agricultura irrigada, como forma de avaliar a qualidade da água para fins de irrigação e abastecimento humano. A maior salinidade em amostras coletadas no Ponto de Controle (P2) e possíveis correlações com o escoamento agrícola foram encontrados por Monteiro et al. (2019).

Nas Figuras 5I e 5J, as amostras de água coletadas evidenciaram os elevados teores para os parâmetros dureza e alcalinidade no Ponto da Controle (P2), local com forte influência das atividades e cultivos agrícolas. Os valores da variável dureza total encontrados no Ponto de Controle (P2) foram superiores em todo o período estudado aos valores encontrados na Barragem (P1) e variou de 514,1 a $2.350 \mathrm{mg} \mathrm{L}^{-}$ 1. Para o consumo humano estas variáveis indicam sabor desagradável, na irrigação provoca efeitos de incrustações nas tubulações. O Ponto de Controle (P2), também apresentou maior variação dos valores (476 a 699,30 $\mathrm{mg} \mathrm{L}^{-}$ $\left.{ }^{1}\right)$ e assim como a dureza, os altos valores conferem à água sabor desagradável (LORDELO et al., 2018).

\section{Indicadores Biológicos da Qualidade da Água}

Nos dois pontos amostrados e em qualquer época do estudo foram encontrados a presença de Coliformes Termotolerantes (Coli), cujos valores encontrados variaram entre 79

a

6.800 NPM 100 $\mathrm{mL}^{-1}$ (Figura 6A). Este fato pode estar relacionado ao livre acesso de animais especialmente bovinos para dessedentação animal e isso se torna preocupante pelo uso da água da barragem para fins de abastecimento humano. 
Sales et al.
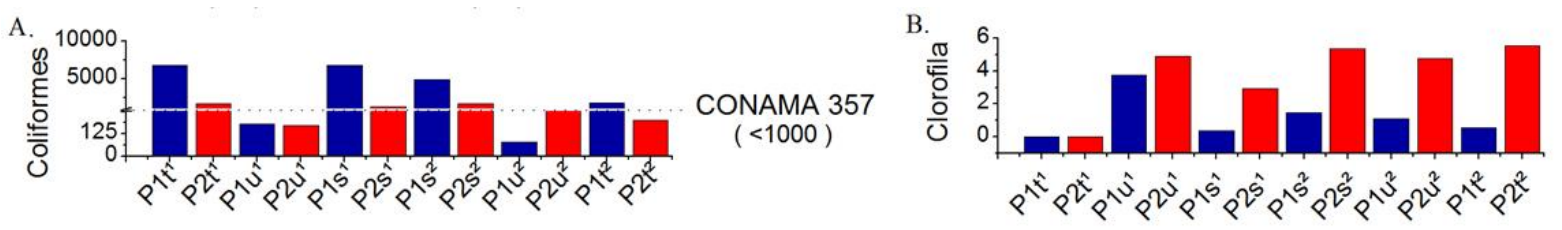

Figura 6. Resultados dos indicadores biológicos da qualidade da água na Bacia Escola Jacaré Curituba em três períodos de amostragem [seco(s), úmido(u) e a transição(t)] entre os anos de 2018 a 2019.P1(Barragem) e P2(Ponto de Controle).

Vale lembrar que durante o período seco em ambos os locais e no período de transição, na barragem, os valores de Coli foram superiores aos valores máximos permitidos pela resolução 357 do CONAMA (BRASIL, 2005), que é de $1.000 \mathrm{NPM} 100 \mathrm{~mL}^{-1}$. A presença dos coliformes na água pode ser prejudicial ao ser humano diante da possibilidade da existência de microrganismos patogênicos, responsáveis pela transmissão de doenças de veiculação hídrica.

Os coliformes são uma variável importante em relação ao uso da água para fins de irrigação, pela possibilidade de conter microrganismos causadores de doenças. Ressalta-se que a ANVISA - Agência Nacional de Vigilância Sanitária por meio da resolução RDC $n^{\circ} 12$, de 2 de janeiro de 2001, estabelece limites microbiológicos para Coliformes Termotolerantes em hortaliças e frutas in natura para consumos direto e fresco podendo até o limite

100 NPM 100mL-1 (BRASIL, 2001).

No que se refere aos valores de Clorofilaa registrada nesta pesquisa, na Figura 6B são apresentadas as variações no período seco (escala de 0,38 a $\left.5,35 \mu \mathrm{g} \mathrm{L}^{-1}\right)$, transição $(0,01$ a $5,52 \mu \mathrm{g} \mathrm{L}^{-1}$ ) e chuvoso (escala de 1,12 a 4,91 $\left.\mu \mathrm{g} \mathrm{L}^{-1}\right)$. O Ponto de Controle (P2) em relação à Barragem (P1) apresentam maiores valores durante todos os períodos estudados.

\section{Parâmetros de Qualidade da Água para fins de Irrigação e Grau de restrição segundo a FAO}

A presença de teor de sais dissolvidos totais (STD) sob a forma de íons oriundos de fontes naturais (erosão e dissolução de rochas) ou antrópicas (escoamento agrícolas), a carga de SDT na Barragem (P1) mostrou uma média igual a $47,91 \mathrm{mg} \mathrm{L}^{-1}$, enquanto que os valores obtidos no Ponto de Controle (P2) em média foram equivalentes à $1.409,17 \mathrm{mg} \mathrm{L}^{-1}$ (Figura 7A), portanto superior ao valor máximo permissível pelo CONAMA 357 (até $500 \mathrm{mg} \mathrm{L}^{-1}$ ) (BRASIL, 2005) e de acordo com a FAO (AYERS e WESTCOT, 1994), apresenta um grau de restrição de uso moderado para valores entre 450 a $2.000 \mathrm{mg} \mathrm{L}^{-}$ 1. Ressalta-se a forte influência de áreas agrícolas no Ponto de Controle (P2) enquanto que na Barragem (P1) a água vem do rio São Francisco por adutoras.

Outro modo de avaliar o teor de sais na água é por meio da condutividade elétrica (CE), sendo que os resultados apresentaram as maiores variações entre os locais de amostragem, apresentando valores mais baixos equivalentes à $0,007 \mathrm{dS}$ m-1 para a Barragem (P1) e valores elevados no Ponto de Controle (P2) igual à 3,97 dS m-1 (Figura 7B).

Este padrão de aumento, valores mais elevados encontrados no ponto de controle (P2) em relação a barragem (P1), ocorre tanto no período chuvoso quanto no seco. Ressalta-se que a água da barragem abastece a irrigação localizada nos lotes do Assentamento Rural Jacaré Curituba, enquanto os escoamentos gerados por excedente na irrigação drenam superficialmente e subsuperficialmente para o riacho estudado. Os elevados valores de condutividade elétrica (>0,1 dS m-1) permitem inferir que esses ambientes apresentam muitos íons dissolvidos na água, oriundos possivelmente da água de drenagem agrícola. Segundo Silva et al., (2019), em estudos sobre a recuperação de solos salinos no mesmo Assentamento Rural, afirmam que os solos salinizaram por excesso da água da irrigação. 
A.

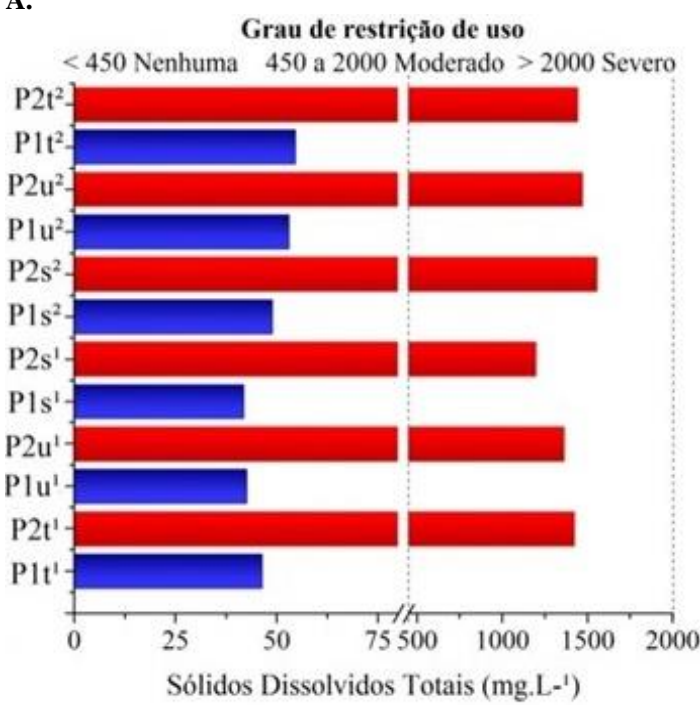

C.

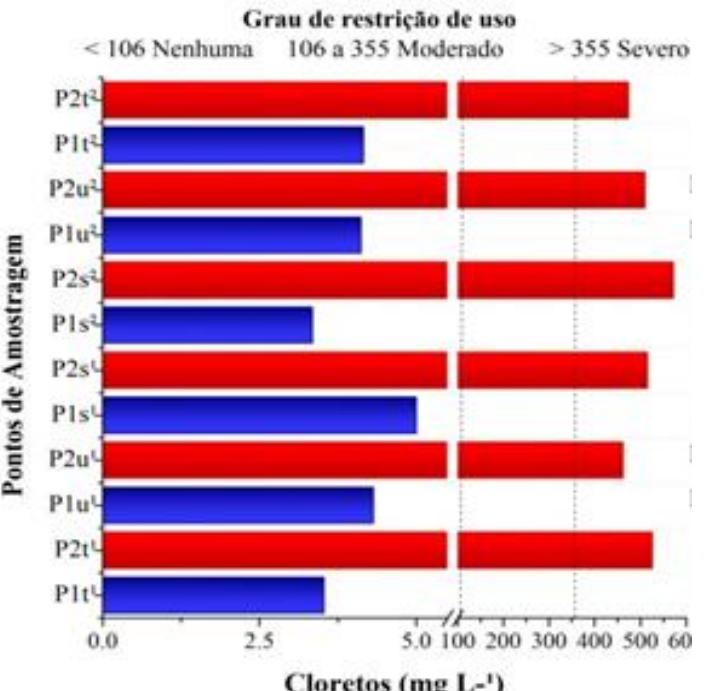

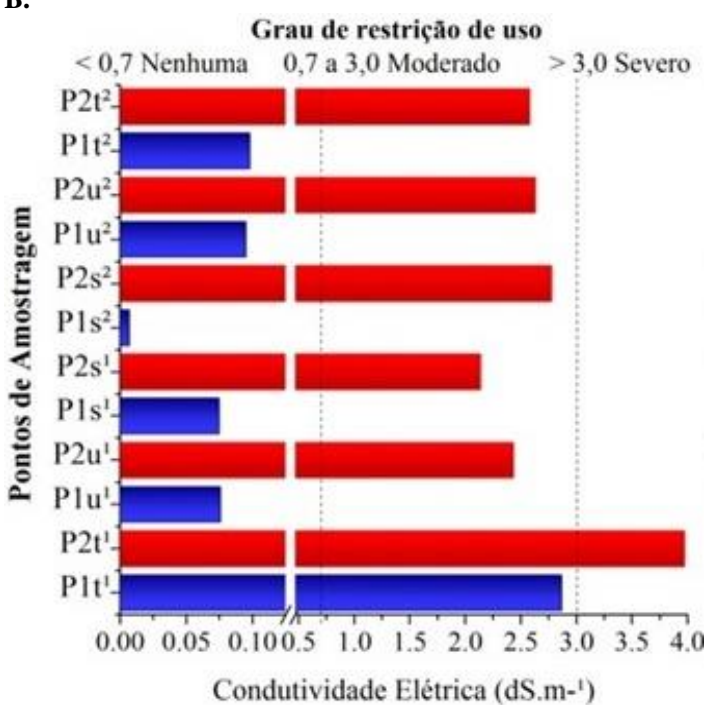

D.
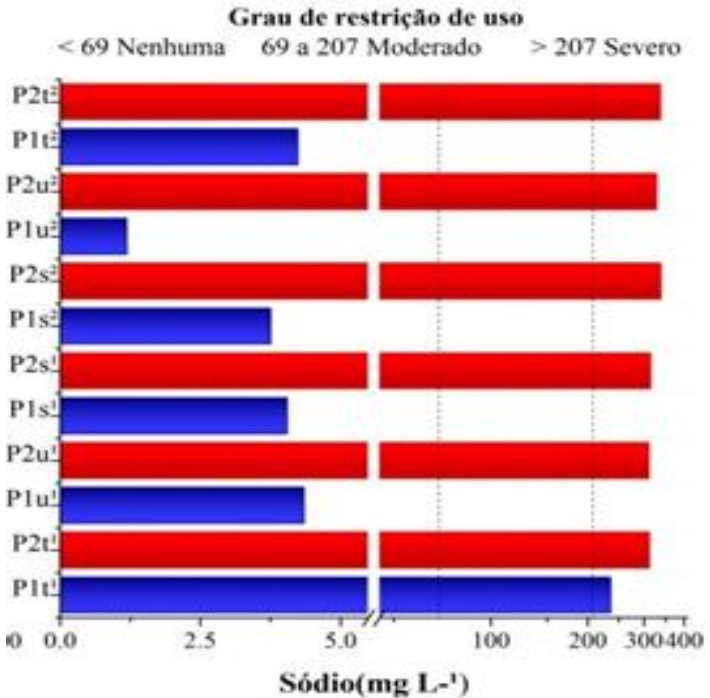

Figura 7. Resultados dos parâmetros de qualidade da água para fins de irrigação na bacia escola Jacaré Curituba em três períodos de amostragem (s-seco, u-úmido e a t-transição) entre os anos de 2018 a 2019, e os respectivos graus de restrição de uso segundo a FAO.

Menezes et al. (2016) sugerem que após a passagem por lotes irrigados a água retorna com uma qualidade deteriorada possivelmente devido ao mau uso do solo e da água nos cultivos agrícolas. Esse resultado corrobora com o de Silva et al. (2019), ao detectarem elevação nos valores de condutividade elétrica no solo.

$\mathrm{Na}$ Figura 7C e 7D pode-se visualizar os valores obtidos para os íons dissolvidos de sódio $\left(\mathrm{Na}^{+}\right)$e cloretos $\left(\mathrm{Cl}^{-}\right)$que apresentaram elevadas concentrações, superiores a $207 \mathrm{mg} \mathrm{L}^{-}$ ${ }^{1}$ para sódio e maiores que $355 \mathrm{mg} \mathrm{L}^{-1}$ para os cloretos no Ponto de Controle da Bacia Escola Jacaré Curituba (P2). Assim, pode-se afirmar que no Ponto de Controle (P2) ocorreu aumento dos valores de sólidos dissolvidos totais, sódio, cloretos, dureza, alcalinidade, condutividade e salinidade em todos os períodos das análises, em comparação a Barragem (P1). A passagem da água por áreas agrícolas irrigadas resulta em problemas de qualidade, devido ao manejo inadequado do solo e da água (MONTEIRO et al., 2019; SILVA et al., 2019).

\section{Classificação das Águas para fins de Irrigação}

De acordo com as diretrizes adotadas para análise no diagrama de classificação das águas para fins de irrigação (Figura 8), indiferente ao período do ano e local, a qualidade da água no Ponto de Controle (P2) apresentou as Classes C4 (águas de salinidade 
muito alta com condutividade elétrica entre 0,75 a $2,25 \mathrm{dS} \mathrm{m}^{-1}$ ), confirmando a perda de qualidade da água entre os pontos 1 e 2 na Bacia Escola Jacaré Curituba.

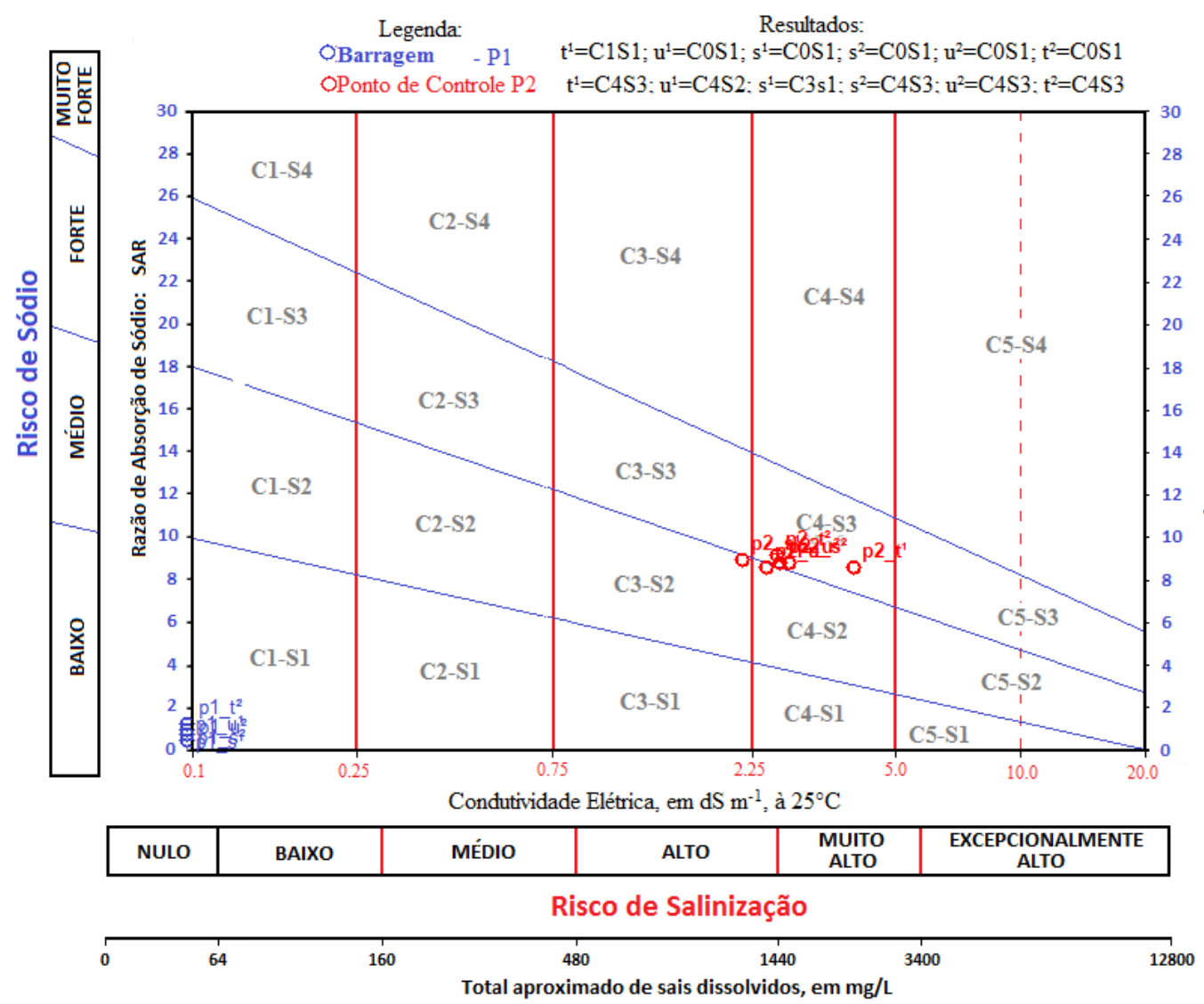

Figura 8. Diagrama de classificação das águas para fins de irrigação da Bacia Escola Jacaré Curituba.

Verifica-se que $83 \%$ das amostras das águas coletadas no Ponto de Controle (P2) apresentaram CE superior a 2,25 dS m $\mathrm{m}^{-1}$, portanto impróprias para fins de irrigação. $\mathrm{O}$ Diagrama também apresenta resultados que indicam a boa qualidade da água do no reservatório (P1), $\mathrm{C}_{1} \mathrm{~S}_{1}$, ou seja, águas de salinidade e sodicidade reduzidas, que podem ser utilizadas sem restrições para irrigação e revelam importância da preservação e manutenção desse manancial, devendo-se mitigar o livre acesso de animais e os descartes de resíduos próximos a barragem, que podem favorecer sua deterioração.

Os níveis de sais e nutrientes são impulsionados principalmente pela quantidade e qualidade da água lixiviada de origem agrícola, e trabalhos têm indicado a correlação da drenagem agrícola no processo de degradação da qualidade, da mesma forma que pode limitar a disponibilidade de água em regiões a jusante (VAN VLIET et al., 2017; HU et al., 2019).

\section{CONCLUSÕES}

Os principais impactos na qualidade da água da bacia escola Jacaré Curituba foram observados no período seco.

O escoamento de áreas agrícolas a montante está afetando a qualidade da água e são responsáveis pelo aumento dos parâmetros de salinidade, sódio, condutividade elétrica, cloretos, sólidos dissolvidos totais, alcalinidade, dureza, nutrientes e clorofila-a.

$\mathrm{Na}$ classificação das águas de irrigação houve variação entre as classes $\mathrm{C}_{1} \mathrm{~S}_{1}$ (baixo risco de salinidade e sodicidade) na Barragem (P1) à $\mathrm{C}_{4} \mathrm{~S}_{3}$ (muito alto risco de salinidade $\mathrm{e}$ forte risco de sodicidade) no Ponto de Controle (P2). 


\section{AGRADECIMENTOS}

O presente trabalho foi realizado com apoio à pesquisa através da concessão da bolsa de estudo da Fundação de Apoio à Pesquisa e à Inovação Tecnológica do Estado de Sergipe FAPITEC/SE auxílio (EDITAL FAPITEC/SE/FUNTEC/CAPES Nº. 05/2017); E ao projeto Opará: águas do rio São Francisco, executado pela Universidade Federal de Sergipe e Sociedade Socioambiental Canoa de Tolda, com patrocínio de Petrobras por meio do Programa Petrobras Socioambiental.

\section{REFERÊNCIAS BIBLIOGRÁFICAS}

AGUIAR NETTO, A. O.; SANTANA, L. L; ALMEIDA, C. A. P.; FACCIOLI, G. G.; SALES, J. M. J. Efeito da variabilidade de cenários de uso do solo sobre a dinâmica da vazão e de sedimentos na bacia hidrográfica do rio Jacaré-SE. In: FAPITEC. (Org.). Pesquisa em políticas públicas no estado de Sergipe. 1ed.São Cristóvão: EDUFS, 2016, v.1, p.267280 .

APHA. American Public Health Association. Standard methods for the examination of water and wastewater. 23th ed. Washington; 2017.

AYERS, R. S.; WESTCOT, D. W. Water quality for agriculture. 3rd. ed. Rome: FAO, 1994. 174p. FAO. Irrigation and Drainage Paper, 29.

BERTOSSI, A. P. A.; MENEZES, J. P. C.; CECÍLIO, R. A.; GARCIA, G. O.; NEVES, M. A. Seleção e agrumpamento de indicadores da qualidade de águas utilizando Estatística Multivariada. Ciências Agrárias, v.34, n.5, p.2025-2036, 2013. DOI: 10.5433/1679$0359.2013 \mathrm{v} 34 \mathrm{n} 5 \mathrm{p} 2025$

BRASIL. Ministério da Saúde. Agência Nacional de Vigilância Sanitária (ANVISA). Resolução RDC n ${ }^{\circ} 12$, de 2 de janeiro de 2001. Aprova Regulamento Técnico sobre Padrões Microbiológicos para Alimentos e seus anexos I e II. Diário Oficial [da] República Federativa do Brasil. Brasília, DF, 10 jan. 2001, Seção 1, n.7-E, p.45.

BRASIL. Ministério do Desenvolvimento Urbano e Meio Ambiente. Conselho Nacional do Meio Ambiente (CONAMA). Resolução n. 357 de 17 de março de 2005. Classificação de corpos d'água e diretrizes ambientais. Brasília: Ministério do Meio Ambiente, 2005. 23p.

BRITTO, F. B.; SILVA, T. M. M.; VASCO, A. N.; AGUIAR NETTO, A. O.; CARVALHO, C. M. Impactos da produção do arroz inundado na qualidade da água do Rio Betume, Sergipe. Agropecuária Técnica, v.37, n.1, p.44-54, 2016. DOI: 10.25066/agrotec.v37i1.25254

BRITTO, F. B.; VASCO, A. N.; AGUIAR NETTO, A. O.; GARCIA, C. A. B.; MORAES, G. F. O.; SILVA, M. G. Surface water quality assessment of the main tributaries in the lower São Francisco River, Sergipe. Revista Brasileira de Recursos Hídricos, v.23, p.1-11, 2018. DOI: $10.1590 / 2318-0331.231820170061$

CARVALHO, L. L. S.; LACERDA, C. F.; ANDRADE, E. M.; LOPES, F. B.; VALNIR JÚNIOR, M.; CARVALHO, C. M. Variabilidade espacial e temporal da qualidade da água de poços no perímetro irrigado do Baixo Acaraú - CE. Revista Brasileira de Agricultura Irrigada, v.11, n.2, p.1348-1357, 2017a. DOI: 10.7127/rbai.v11n200623

CARVALHO, L. L. S.; LACERDA, CARVALHO, C. M.; C. F.; LOPES, F. B.; ANDRADE, E. M.; GOMES FILHO, R. R. Variabilidade espaço-temporal da qualidade das águas subterrâneas em área irrigada no semiárido brasileiro. Research, Society and Development, v.9, n.8, e644985786, 2020a. DOI: $10.33448 /$ rsd-v9i8.5786

CARVALHO, L. L. S.; LACERDA, C. F.; LOPES, F. B.; ANDRADE, E. M.; CARVALHO, C. M.; SILVA, S. L. Caracterização dos usos das águas subterrâneas no perímetro irrigado do Baixo Acaraú - CE. Revista de Agronegócio e Meio Ambiente, 
v.13, n.2, p.601-620, 2020b. DOI: 10.17765/2176-9168.2020v13n2p601-620

CARVALHO, L. L. S.; LACERDA, C. F.; LOPES, F. B.; CARVALHO, C. M.; GOMES FILHO, R. R.; ARAÚJO FILHO, R. N. Influence of Prolonged Drought on Groundwater Quality: Irrigated Perimeter of Lower Acaraú - State of Ceará- Northeast of Brazil. Journal of Experimental Agriculture International, v.18, n.3, p.1-14, 2017b. DOI: 10.9734/JEAI/2017/36480

EMBRAPA. Empresa Brasileira de Pesquisa Agropecuária. Sistema brasileiro de classificação de solos. 5.ed. revisada e ampliada, Brasília-DF: Embrapa, 2018. 356p.

EWAID, S. H.; ABED, S. A.; KADHUM, S. A. Predicting the Tigris River Water Quality within Baghdad, Iraq by Using Water Quality Index and Regression Analysis. Environmental Technology \& Innovation, v11, p.390-398. 2018. DOI: 10.1016/j.eti.2018.06.013

HU, Q.; YANG, Y.; HAN, S.; WANG, J. Degradation of agricultural drainage water quantity and quality due to farmland expansion and water-saving operations in arid basins. Agricultural Water Management. v.213. p.185-192, 2019.2 DOI: 10.1016/j.agwat.2018.10.019

KÖPPEN, N. W. Climatologia: com um estudio de los climas de la Tierra. México: Fondo de Cultura Econômica, 1948. 478 p.

KUMAR, P.; THAKUR, P.; BANSOD, B.K.S.; DEBNATH, S. Groundwater: a regional resource and a regional governance. Environment Development and Sustainability, v.20, n.3, p.1133-1151, 2017. DOI: $10.1007 / \mathrm{s} 10668-017-9931-y$

LOMBA, A.; STROHBACH, M.; JERRENTRUP, J. S.; DAURBER, J.; KLIMEK, S.; McCRACKEN, D. I. Making the best of both worlds: Can high-resolution agricultural administrative data support the assessment of High Nature Value farmlands across Europe? Ecological Indicators, v.72, p.118-130, 2017.

10.1016/j.ecolind.2016.08.008

LORDELO, L. M. K.; PORSANI, J. M.; BORJA, P. C. Qualidade físico-química da água para abastecimento humano em municípios do sertão da Bahia: um estudo considerando diversas fontes de suprimento. Águas Subterrâneas, v.32, n.1, p.97-105, 2018. DOI: $10.14295 /$ ras.v32i1.28896

MENEZES, J. P. C.; BITTENCOURT, R. P.; FARIAS, M. S.; BELLO, I. P.; FIA, R.; OLIVEIRA, L. F. C. Relação entre padrões de uso e ocupação do solo e qualidade da água em uma bacia hidrográfica urbana. Engenharia Sanitária e Ambiental, v.21, n.3, p.519-534, 2016. DOI: $10.1590 /$ S1413-41522016145405

MONTEIRO, A. S. C; NASCIMENTO R. S.; SALES, J. M. J.; SILVA, I. S.; AGUIAR NETTO, A. O. Qualidade da água dos rios São Francisco e Jacaré por meio de análise multivariada. In: Simpósio Brasileiro De Recursos Hídricos, 23, Foz do Iguaçu-PR. Anais... Foz do Iguaçu: ABRH, 2019. http://anais.abrh.org.br/works/5160.

RICHARDS, L. A. Diagnosis and improvement of saline and alkali soils. Washington, D.C: United States Salinity Laboratory, 1954. 160 p. (United States Department of Agriculture Handbook, 60).

SALES, J. M. J; BARRETO, S. S; AGUIAR NETTO, A. O. Caracterização da Bacia Escola Jacaré Curituba, em Poço Redondo-SE. In: COSTA, P. R. S. M.; AGUIAR NETTO, A. O. (Org.). Lugares, Potencialidades e Resistências: Terra e Povo no São Francisco. 1ed. Aracaju: Criação, 2018, v.1, p.111-132.

SANTI, G. M.; FURTADO, C. M.; MENEZES, R. S.; KEPPELER, E. C. Variabilidade espacial de parâmetros e indicadores de qualidade da água na sub-bacia hidrográfica do Igarapé São Francisco, Rio Branco, Acre, Brasil. Ecología Aplicada, v.11, n.1, p.23-31, 2012. 
SASSOMA, I. T. L.; SOUSA, I. F.; AGUIAR NETTO, A. O.; CARVALHO, C. M. Avaliação temporal e espacial de caracteristicas físicoquímicas em águas superficiais do Rio Catumbela, Angola. Revista Brasileira de Agricultura Irrigada, v.9, n.3, p.113-126, 2015. DOI: $10.7127 /$ rbai.v9n300295

SCHINDLER, D. W.; HECKY, R. E.; McCULLOUGH, G. K. The rapid eutrophication of lake winnipeg: greening under global change. Journal of Great Lakes Research, v.38, s.2, p.6-13, 2012. 10.1016/j.jglr.2012.04.003

SILVA, A. J.; AGUIAR NETTO, A. O.; LUCAS, A. A. T.; ARAUJO, R. R. Recuperação de solo salino-sódico no semiárido brasileiro. In: Antenor de Oliveira Aguiar Netto; Anny kelly Vasconcelos de Oliveira Lima; Thadeu Ismerin Silva Santos. (Org.). Opará. 1ed.Aracaju: Criação Editora, 2019, v. 1, p. 135-146.

SINGH, A. Environmental problems of salinization and poor drainage in irrigated areas: management through the mathematical models. Journal of Cleaner Production, v.206, p.572-579. 2019. DOI: 10.1016/j.jclepro.2018.09.211

SKORONSKI, E.; NIERO, B.; FERNANDES, M.; ALVES, M. V.; TREVISAN, V. Study of the application of tannin in the treatment of drinking water from the Tubarão River at Tubarão, SC. Ambiente \& Água, v.9, n.4, p.679-687, 2014. DOI: 10.4136/ambiagua.130
VALLE JÚNIOR, R. F.; ABDALA, V. L.; GUIDOLINI, J. F.; SIQUEIRA， H. E.; CANDIDO, H. G. Diagnostico temporal e espacial da qualidade das aguas superficiais do Rio Uberaba - MG. Caminhos de Geografia, v.14, n.45, p.01-11, 2013.

Van VLIET, M. T. H., FLÖRKE, M., WADA, Y. Quality matters for water scarcity. Nature Geoscience, v.10, n.11, p.800-802, 2017. DOI: 10.1038/ngeo3047

VASCONCELOS, R. S.; LEITE, K. N.; CARVALHO, C. M.; ELOI, W. M.; SILVA, L. M. F.; FEITOSA, H. O. Qualidade da água utilizada para irrigação na extensão da microbacia do baixo Acaraú. Revista Brasileira de Agricultura Irrigada, v.3, n.1, p.30-38, 2009. DOI: 10.7127/rbai.v3n100014

VON SPERLING, M. Estudos de modelagem da qualidade da água de rios. Belo Horizonte: UFMG, 2007. vol.7. 452 p.

XAVIER, A. C.; KING, CAREY, W. S.; BRIDGET, R. Daily gridded meteorological variablesin Brazil (1980-2013). International Journal of Climatology, v.36, n.6, p.26442659, 2015. DOI: $10.1002 /$ joc. 4518

XIE, Y. L.; XIA, D. X.; JI, L.; HUANG, G. H. An inexact stochastic-fuzzy optimization model for agricultural water allocation and land resources utilization management under considering effective rainfall. Ecological Indications, v.92, p301-311, 2018. DOI: 10.1016/j.ecolind.2017.09.026 